\title{
Characteristic expression of twelve rice $P R I$ family genes in response to pathogen infection, wounding, and defense-related signal compounds (121/180)
}

\author{
Ichiro Mitsuhara $\cdot$ Takayoshi Iwai $\cdot$ Shigemi Seo $\cdot$ \\ Yuki Yanagawa $\cdot$ Hiroyuki Kawahigasi $\cdot$ \\ Sakino Hirose $\cdot$ Yasunobu Ohkawa $\cdot$ Yuko Ohashi
}

Received: 21 November 2007 / Accepted: 10 January 2008 / Published online: 5 February 2008

(C) The Author(s) 2008

\begin{abstract}
Pathogenesis-related (PR) proteins have been used as markers of plant defense responses, and are classified into 17 families. However, precise information on the majority members in specific PR families is still limited. We were interested in the individual characteristics of rice PRI family genes, and selected 12 putatively active genes using rice genome databases for expressed genes. All were upregulated upon compatible and/or incompatible rice-blast fungus interactions; three were upregulated in the early infection period and four in the late infection period. Upon compatible rice-bacterial blight interaction, four genes were upregulated, six were not affected, and one was downregulated. These results are in striking contrast to those among 22 Arabidopsis PR1 genes where only one gene was pathogen-inducible. The responses of individual genes to salicylic acid, jasmonic acid, and ethylene induced defense signaling pathways in rice are likely to be different from those in dicot plants. Transcript levels in healthy leaves,
\end{abstract}

Communicated by K. Shirasu.

Ichiro Mitsuhara and Takayoshi Iwai contributed equally to this work.

I. Mitsuhara $(\bowtie) \cdot$ S. Seo $\cdot$ Y. Yanagawa $\cdot$ H. Kawahigasi $\cdot$

S. Hirose $\cdot$ Y. Ohkawa $\cdot$ Y. Ohashi

National Institute of Agrobiological Sciences (NIAS),

Kannon-dai 2-1-2, Tsukuba, Ibaraki 305-8602, Japan

e-mail:mituhara@affrc.go.jp

T. Iwai

Miyagi Prefectural Agriculture and Horticulture Research Center,

Takadate-kawakami, Natori, Miyagi 981-1243, Japan

Present Address:

Y. Yanagawa

Nara Institute of Science and Technology,

The Graduate School of Biological Sciences,

Ikoma, Nara 630-0101, Japan roots, and flowers varied according to each gene. Analysis of the partially overlapping expression patterns of rice $P R I$ genes in healthy tissues and in response to pathogens and other stresses would be useful to understand their possible functions and for use as characteristic markers for defenserelated studies in rice.

Keywords Bacterial blight · Histological analysis . Defense gene expression - Pathogen resistance .

$\mathrm{PR}$ protein $\cdot$ Rice

\section{Introduction}

Pathogenesis-related (PR) proteins, which are classified into 17 families, accumulate after pathogen infection or related situations in many plant species (van Loon et al. 2006). Among the $P R$ gene family, $P R I$ genes have been frequently used as marker genes for systemic acquired resistance in many plant species. However, only a small proportion of $P R I$ genes have been studied among the many members in this family, and information on the other members is limited. For example, NtPRla, $b$, and $c$ genes for acidic proteins, and NtPRBI (PR-1g) and NtPRBIb genes for basic proteins were reported in tobacco (Nicotiana tabacum) (van Loon and van Strien 1999), but little information is known on other PRI members. To understand the characteristics and redundancy of the majority of PRI family members, genome-based studies are necessary. For such studies, dicot Arabidopsis and monocot rice (Oryza sativa L.) plants have been used as the model plants.

In Arabidopsis, 22 genes are listed as predicted PRI genes that encode homologous proteins to tobacco PR1a protein, which was first reported as an acidic protein in tobacco leaves infected with Tobacco mosaic virus (TMV) 
(van Loon et al. 2006). Among the 22 genes, only one PRI gene (At2g14610), which encodes a basic protein, is known to be pathogen-responsive, and the other PRI genes reportedly did not respond to either bacterial or fungal pathogens (van Loon et al. 2006). From these results, we tend to suppose that only one $P R I$ gene relates to pathogen resistance in Arabidopsis and the others contribute to other functions.

In rice, the induction of two $P R I$ genes, OsPRIa and $1 b$, by blast fungus infection was reported (Agrawal et al. 2001). They encode putative acidic and basic proteins, respectively, and also responded to environmental stresses and treatments with some chemicals (Agrawal et al. 2000a, b). However, for other rice PRl gene family members, there is only limited information except for their presence and expression: (1) at least 4 signals for possible rice PR1 proteins responsive to anti-tobacco PR1a antibodies were found in an extract of blast fungus-infected rice leaves (Schweizer et al. 1997; Iwai et al. 2007), and (2) 32 predicted $P R 1$ genes were proposed to be present in the rice genome (van Loon et al. 2006).

To study the response of individual rice $P R l$ genes to pathogens, we selected active rice $P R l$ genes from the rice genome databases for expressed genes, and studied their induced expression by real time RT-PCR (qPCR). In striking contrast with the result in Arabidopsis, all 12 rice genes selected here were upregulated by blast fungus infection. The levels of constitutive expression in organs and induced expression by different treatments varied according to the gene. In addition to the data on tissue-specific $P R I$ expression in transgenic rice with a $O S P R 1$ promoter:: $\beta$-glucuronidase (GUS) fusion gene, we list the characteristics of the 12 rice $P R l$ genes. This is the first example of a comparison of the expression of the majority of members of a monocot $P R$ family to our knowledge. This information will be useful for further studies on $P R$ genes and on resistance mechanism in rice plants.

\section{Materials and methods}

Plant materials

Wild-type (WT) rice (Oryza sativa cv. Nipponbare) and the near isogenic line IL7 (Ise and Horisue 1988), which contains the $R$ gene $P i-i$ against blast fungus (Magnaporthe grisea) race 003 (Yamada et al. 1976), were grown for 1416 days in soil (Bonsol No. 1, Sumitomo Chemicals L., Japan) in a greenhouse at $28^{\circ} \mathrm{C}$ in the day time and $25^{\circ} \mathrm{C}$ at night. The fourth leaves of plants at the 4-leaf stage were mainly used as the experimental material. The seeds of transformants with $O S P R 1:: G U S$ were germinated on agar medium containing $30 \mu \mathrm{g} \mathrm{ml}^{-1}$ hygromycin, transferred to soil at 7 days after imbibition, and grown in the greenhouse. Five-day-old seedlings on agar medium and 2-month-old plants in the greenhouse were used for GUS-staining assays.

Infection with pathogens

Magneporthe grisea race 003 (isolate Kyu-89-241) was grown on oat-meal medium (Difco) for 2 weeks and conidia were induced under BLB light (FL20S BLB, Toshiba) for 2 days at $25^{\circ} \mathrm{C}$. The rice seedlings of Nipponbare and IL7 plants at the 4-leaf stage were spray-inoculated with a conidia suspension $\left(1 \times 10^{5}\right.$ conidia $\left.\mathrm{ml}^{-1}\right)$ containing $0.05 \%$ Tween 20 , and the inoculated plants were incubated under high humidity in the dark for $20 \mathrm{~h}$, and then moved to the greenhouse. Under these conditions, about 100 local lesions were induced per leaf on Nipponbare and IL7. For bacterial blight infection, Nipponbare plants, which are compatible with Xanthomonas oryzae pv. oryzae (Xoo) strain T7174 (race I, MAFF 311018), were inoculated by cutting the leaf top with scissors that had been dipped in a suspension containing $10^{8} \mathrm{cfu} / \mathrm{ml}$ of $X o o$, and incubated in the greenhouse.

\section{Treatment with chemicals}

Plastic pots $(15 \times 5.5 \times 10 \mathrm{~cm})$ with 12 rice seedlings at the 4-leaf stage, were dipped in $500 \mathrm{ml}$ solutions containing $1 \mathrm{mM}$ 1-aminocyclopropane-1-carboxylic acid (ACC) or $3 \mathrm{mM}$ sodium salicylate (SA) solution, and incubated for $24 \mathrm{~h}$ in the greenhouse. For jasmonic acid (JA) treatment, pots with 12 seedlings each was put in an air-tight clear plastic box, and a cotton pad with volatile methyl jasmonate (MeJA) dissolved in EtOH was put at the corner of the box to give a final concentration of $100 \mu \mathrm{M}$, and incubated for $24 \mathrm{~h}$. The fourth leaves were used for RNA extraction.

\section{Quantitative real-time RT-PCR}

To analyze the response of $O s P R l$ genes to biotic and abiotic stresses, quantitative real-time RT-PCR (qPCR) was conducted using iQ SYBR Green Supermix (BioRad, Hercules, CA, USA) and an iCycler (BioRad) according to the manufacturers' instructions. At least three independent biological samples were used with specific primers for each individual gene (Table 2). The data were normalized by the value of an actin gene (AK060893), and fold change in the expression level was calculated compared with that of healthy fourth leaves, and standard deviation (SD) values are shown. 
Construction of plasmids for transformation of rice

The promoter region of the OsPR1.1 gene (OsPRI\#074 in this work) was obtained through PCR amplification from the Nipponbare genome, using a GenomeWalker ${ }^{\mathrm{TM}}$ kit (Invitrogen, CA, USA) in accordance with the manufacturer's instructions (Accession no. AP008213, Kawahigashi et al. 2007). The amplified fragment was digested by NotI and BamHI and inserted into the pTH2 vector to construct the PR1T::GUS plasmid (Fig. 7a). The PR1T::GUS plasmid contained $1,919 \mathrm{bp}$ of the promoter and the coding region for 16 amino acids at the N-terminus of the $O s P R 1$ gene to express a fused GUS protein effectively (Kawahigashi et al. 2007).

\section{Transformation of rice}

Agrobacterium tumefaciens LB4404 was transformed with the constructed vector (Kawahigashi et al. 2007). The transformation of rice was performed by Agrobacterium infection as described by Toki et al. (2006).

\section{Histological GUS analysis}

Histological analysis for GUS activity was performed at $37^{\circ} \mathrm{C}$ essentially as described by Ohshima et al (1990) using a modified reaction mixture: $50 \mathrm{mM}$ phosphate buffer (pH 7.0) containing $1 \mathrm{mM}$ 5-bromo-4-chloro-3-indolyl glucuronide (X-gluc), 5\% methanol, $10 \mu \mathrm{g} / \mathrm{ml}$ cycloheximide, and $1 \mathrm{mM}$ dithiothreitol. The reaction was stopped by the addition of ethanol.

\section{Results}

Characterization of the rice $P R l$ gene family

Using the amino acid sequence of the mature tobacco acidic PR1a protein (NtPR1a; 138 amino acids, Ohshima et al. 1987) as the probe, we searched for expressed genes in rice (Oryza sativa cv. Nipponbare) encoding homologous proteins with a similar size range (within 150-200 amino acids) using a full-length cDNA database (http:// www.cdna01.dna.affrc.go.jp/cDNA) and rice EST database (http://www.riceblast.dna.affrc.go.jp/). The presence and location of these genes were confirmed in the genome database of rice (http://www.rapdb.dna.affrc.go.jp/). After removing repetitive clones and confirmation of the sequences, finally 12 genes were selected as candidates for active rice $P R l$ genes, which encode proteins with sequences $\geq 41 \%$ identical to that of tobacco PR1a protein at least in the C-terminal 65 amino acids. Previously, two rice $P R 1$ genes were reported to encode an acidic PR 1a protein and a basic PR1b protein (Agrawal et al. 2000a), which were upregulated by blast fungus infection. In addition to the two, we found another 10 active genes on chromosomes 1, 2, 5, 7, 10, and 12 (Table 1). Proposed names were given to distinguish each gene to avoid confusion in this study according to the location on the chromosomes. For example, OsPR1b (AK107926, Os01g28450), located on the 5' side of the gene for AK121108 (Os01g28500) on chromosome 1, was designated as OsPRI\#011 and AK121108 was OsPRI\#012. On chromosome 7, four PRl-like genes, OsPR1\#071, \#072, \#073, and \#074, were clustered in

Table 1 Classification of rice $P R 1$ protein genes

\begin{tabular}{|c|c|c|c|c|c|}
\hline Plant & Accession No. (Symbol name) & Locus name & References & PI & Proposed symbols \\
\hline \multirow[t]{12}{*}{ Rice } & AK107926 (OsPR1b) & Os01g28450 & Agrawal et al. (2000b) & 7.6 & OsPRI\#011 \\
\hline & AK121108 & Os01g28500 & - & 8.7 & OsPRI\#012 \\
\hline & AK107467 & Os02g54540 & - & 8.5 & OsPRI\#021 \\
\hline & AK105575 & Os02g54560 & - & 5.9 & OsPRI\#022 \\
\hline & AK071326 & Os05g51660 & - & 7.1 & OsPRI\#051 \\
\hline & AK100748 & Os05g51680 & - & 5.5 & OsPRI\#052 \\
\hline & AK060057 & Os07g03279 & - & 4.2 & OsPRI\#071 \\
\hline & AK062949 & Os07g03580 & - & 4.7 & OsPRI\#072 \\
\hline & AK063248 & Os07g03590 & - & 5.8 & OsPRI\#073 \\
\hline & AU163470 (OsPR1a) & Os07g03710 & Agrawal et al. (2000a) & 4.4 & OsPRI\#074 \\
\hline & AU070895 & Os $10 \mathrm{~g} 11500$ & - & 10.7 & OsPRI\#101 \\
\hline & AK100940 & Os12g43700 & - & 5.1 & OsPRI\#121 \\
\hline \multirow[t]{2}{*}{ Arabidopsis } & $(P R-1$ like $)$ & At2g19990 & Metzler et al. (1991) & 6.0 & \\
\hline & $(A t P R B 1)$ & At2g14580 & Santamaria et al. (2001) & 8.8 & \\
\hline \multirow[t]{2}{*}{ Tobacco } & $\begin{array}{l}\mathrm{X} 06361(N t P R 1 a) \\
\quad(\mathrm{X} 12737, \mathrm{X} 05959, \mathrm{X} 06930)\end{array}$ & & Ohshima et al. (1987) & 4.4 & \\
\hline & X66942 (NtPRB1b) & & Eyal et al. (1992) & 7.6 & \\
\hline
\end{tabular}


tandem from the $5^{\prime}$ side to the $3^{\prime}$ side in the sense orientation in this order. The predicted isoelectric point $(\mathrm{pI})$ of each mature protein is shown in Table 1 for reference. The amino acid sequences of the predicted mature proteins for the 12 OsPRI genes were compared with those of representative acidic and basic PR1 proteins from Arabidopsis (AtPR1-like and AtPRB1) and tobacco (NtPR1a and NtPRB1b), respectively (Fig. 1a). The sequences of the 12 OsPR1s, 2 AtPR1s, and 2 NtPR1s listed here are well conserved. As the N-termini of OsPR1\#051, \#052, and \#121 are not conserved, these regions were eliminated for the alignment in Fig. 1a. Ten amino acid residues (closed circles) are completely conserved among the 12 rice, 2 Arabidopsis, and 2 tobacco genes, indicating they are important for the predicted roles of PR1 proteins.

Using the data of Fig. 1a, a phylogenetic tree was constructed (Fig. 1b). Among the 12 OsPR1 proteins, 7 acidic and 4 basic protein members were found (Fig. 1b). The C-terminal region of OsPR1\#051 was indicated to be

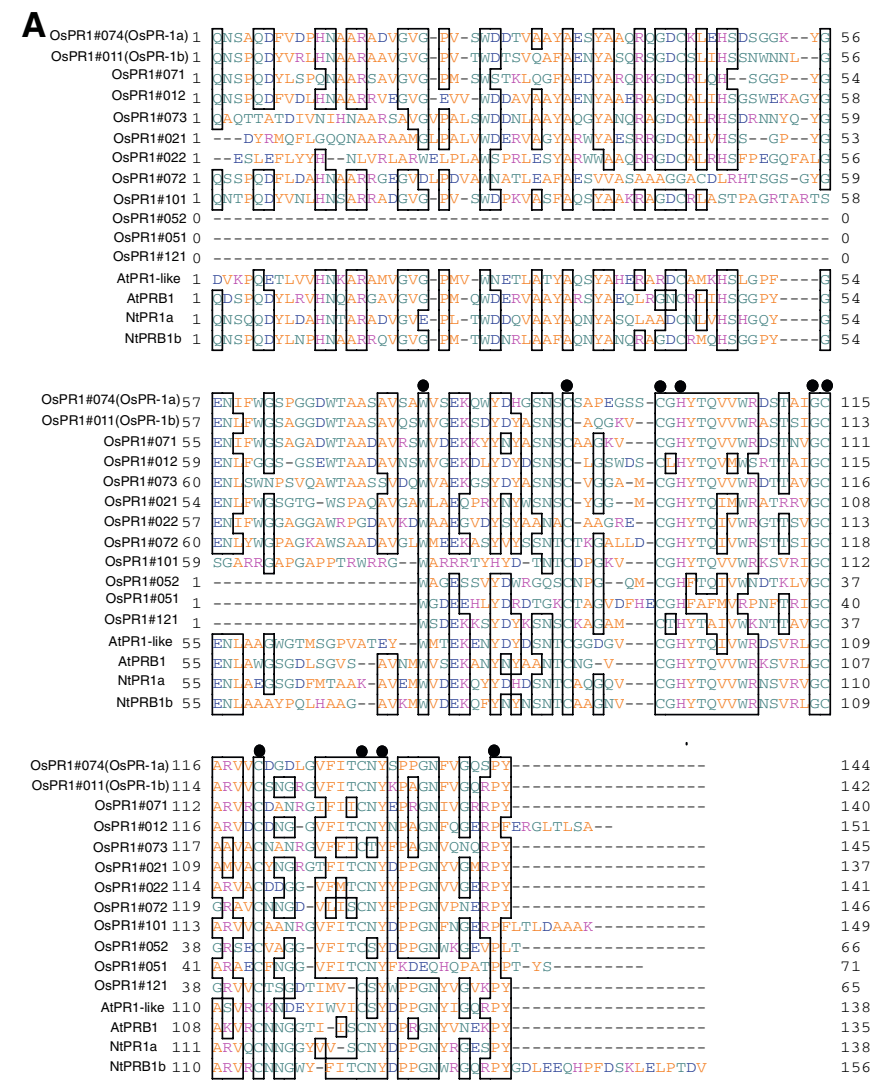

Fig. 1 Characterization of the $P R 1$ gene family in rice plants. a Amino acid sequence alignment of 12 putative PR1 proteins from rice. The predicted mature proteins encoded by these genes were aligned by GENETICS 9.0 (Software Development Co., Tokyo). Because the Ntermini of OsPR1\#052, \#051, and \#121 are considerably different from those of the other 9 OsPR1s, these regions were eliminated from the figure and the conserved C-termini among the 12 OsPR1s were aligned. The acidic and basic PR1 proteins from Arabidopsis (AtPR1-like and neutral. The PR1 proteins from Arabidopsis and tobacco grouped in one clade (framed), and OsPR1 proteins belonged to different clades.

Responses of OsPR1 genes to blast-fungus infection in young rice plants

\section{Compatible interaction}

The response of individual $O S P R 1$ genes to blast-fungus infection was analyzed by qPCR using a set of primers specific for each gene (Table 2). A conidia suspension of $M$. grisea race 003 was sprayed on the seedlings of Nipponbare at the four-leaf stage. In this system, the fungus infection results in the formation of whitish expanding lesions at 3 days post inoculation (dpi), and increasing lesion size thereafter with conidia formation. The infected plants were severely wilted and died within 7-9 days indicating a typical compatible host-parasite interaction (Sasaki et al. 2004;

B

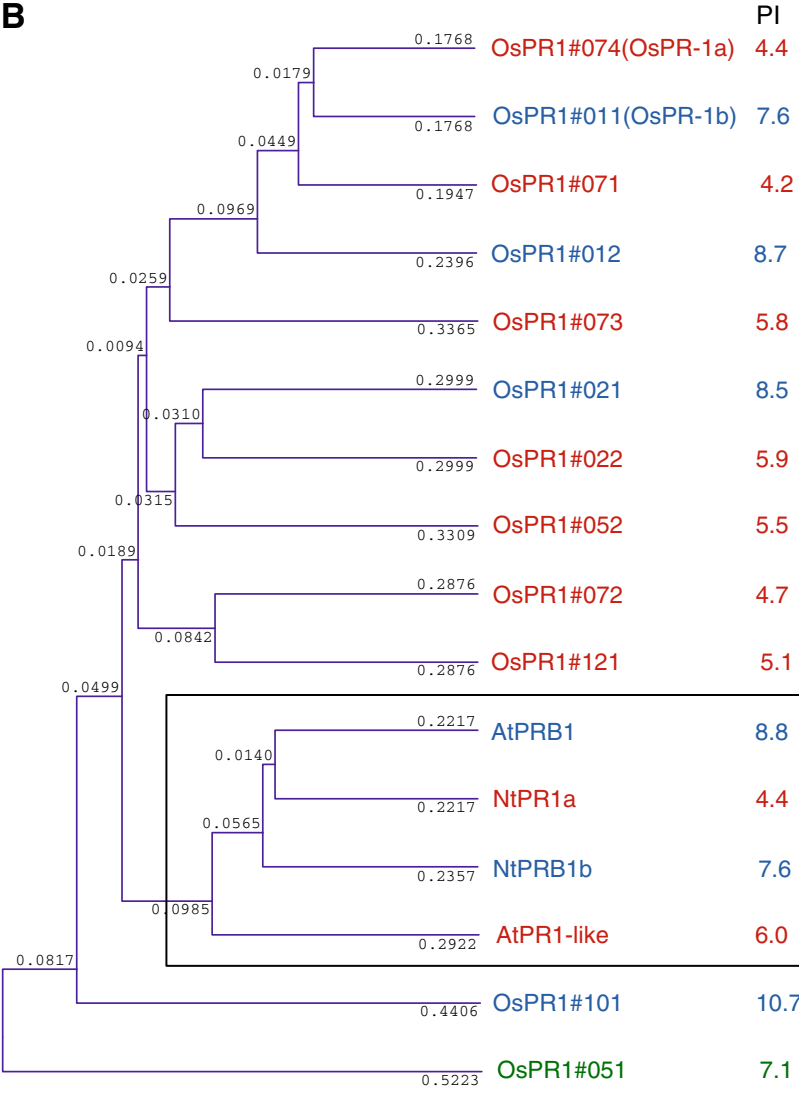

AtPRB1) and tobacco (NtPR1a and NtPRB1b) were used as representatives of acidic and basic PR1 proteins, respectively. The conserved amino acid residues among the 16 proteins are marked with black circles. Identical amino acids are boxed. b Phylogenetic analysis of rice PR1 proteins based on the mature proteins using UPGMA method. The predicted isoelectric point $(p I)$ for each mature protein is shown on the right. Acidic, basic, and neutral proteins are shown in red, blue, and green, respectively. Refer to the description in a for details 
Table 2 Primers for qPCR of $O s P R 1 \mathrm{~s}$ and actin genes

\begin{tabular}{|c|c|c|}
\hline Name & Forward primer & Reverse primer \\
\hline OsPRI\#074 & GTATGCTATGCTACGTGTTTATGC & GCAAATACGGCTGACAGTACAG \\
\hline OsPRI\#011 & ACGCCTTCACGGTCCATAC & AAACAGAAAGAAACAGAGGGAGTAC \\
\hline OsPRI\#071 & CTTTAACTATGTATGGAGTATGATATAAATGTG & TTATTTTCTTCTTTTATTCGAACGACAAC \\
\hline OsPRI\#012 & CGCTGTGTGTTTGTGTTATGTC & CGTGGTTTTGTCTTTATTTCAATCC \\
\hline OsPRI\#073 & TTATATATGTATGTTCGTATGTATGTATGC & TGATGTACTTATTCCATCCGACAC \\
\hline OsPRI\#021 & CGCAGCAACCAACCAATCTTG & ACAGTTGTAGTACTCTTGTAACATCATC \\
\hline OsPRI\#022 & CCACAGAGTTTGTCAGGATTGTC & CAGATTGCACACACCTGATTCC \\
\hline OsPRI\#052 & AGCTACCTGTCATTTCTTCATTTC & TGCTACTCCAGAAGGAAATTAAAAG \\
\hline OsPRI\#072 & AATTAATACTGGAGTAGATGCATGTAC & ACGAATAACGTACTGTATTCTGTATG \\
\hline OsPRI\#121 & ACCATCGTCGTCGTCTCATC & AGCCTCTAGGGCATATCACTAAC \\
\hline OsPRI\#101 & TCGCTGCCGCTAGTACATTTC & ATTAAGATCATTACATGCTTTATTGTTCAC \\
\hline OsPRI\#051 & CCTGCCTGCCTTCCTCATTC & AGTGAAGATTTGGTTTCCATTGTATTG \\
\hline Actin & GAGTATGATGAGTCGGGTCCAG & ACACCAACAATCCCAAACAGAG \\
\hline
\end{tabular}

Iwai et al. 2006). Using triplicate cDNA samples originating from independently prepared RNA templates from inoculated fourth leaves, the expression levels of each gene were compared with that of an actin gene, which was selected as a control gene. Although expression levels of OSPRI genes in healthy Nipponbare leaves varied according to each gene ( $0 \mathrm{dpi}$, white column in Fig. 2a), all OSPRI genes tested were up-regulated by blast-fungus inoculation at 3 and/or 6 dpi (black column). When compared with mock-inoculation (gray column), the enhanced expression by the fungus was significant for each gene at 6 $\mathrm{dpi}$, at which lesions were vigorously expanding. The transcripts of OsPRI\#074, \#011, and \#012 had already accumulated to near maximal levels at 3 dpi maintaining almost the same levels at $6 \mathrm{dpi}$, indicating they are rapid response genes to blast fungus infection. However, the transcripts of OsPR1\#073, \#022, \#101, \#051, and \#121 had not increased significantly at 3 dpi compared with mock-inoculated controls, indicating these are late response genes. Blast fungus infection induced around 1,000-fold transcript accumulation at 6 dpi compared with 0 dpi in 7 genes: OsPRI\#074, $\# 011$, \#071, \#073, \#052, \#072, \#101, and \#121.

\section{Incompatible interaction}

IL7 is a near isogenic line of Nipponbare, into which the resistance gene $P i-i$ for blast fungus race 003 has been introduced. In fungus-inoculated IL7, small HR lesions were induced at 2 dpi with no remarkable fungal development thereafter, indicating a typical incompatible interaction (Sasaki et al. 2004; Iwai et al. 2006). The transcript levels of OSPRI\#074, \#011, and \#012 were maximized at $3 \mathrm{dpi}$, and slightly reduced at 6 dpi (Fig. 2a, lower part, gray arrowheads), indicating they are early responsive genes to blast fungus infection. The 3 genes had been recognized as early responsive genes in compatible interaction. The levels of OsPRI\#074 and \#011 transcripts increased by about 1,000-fold at 3 dpi. The transcripts of OsPR1\#071, \#072, \#073, and \#101 were higher at at $6 \mathrm{dpi}$ than at $3 \mathrm{dpi}$, indicating they are late responsive genes (black arrowheads). The level of OsPRI\#121 was suppressed by mock-inoculation but the level was not changed by incompatible interaction. OsPRI\#051, whose transcript increased in the compatible interaction at $6 \mathrm{dpi}$, was not clearly upregulated in the incompatible interaction.

Responses of OsPR1 genes to bacterial blight infection in young rice plants

To study the response of the 12 OsPRI genes to a bacterial pathogen, the fourth leaves of Nipponbare were inoculated with Xoo for leaf blight disease. In the compatible rice-bacterium interaction, the infected region was visualized as wilted necrosis, which spread from the cross cut end to the leaf base with time, and the area of necrosis grew to 2-3 cm long at 8 dpi. At 4 and 8 dpi, $5 \mathrm{~cm}$ long leaf pieces from the inoculated point were used to prepare RNA samples. Transcripts of OsPRI\#074, \#011, and $\# 012$, which are early responsive genes to blast fungus (Fig. 2a), accumulated remarkably at both 4 and 8 dpi compared with 0 dpi or a mock-inoculated control (Fig. 2b), indicating they were responsive to Xoo infection (closed forward arrowheads). Expression of OsPRI\#021 and \#022 were slightly suppressed after the infection compared with mock-inoculated leaves (closed reverse arrowheads). Expression of OsPR1\#074, \#011, \#012, and \#101 were upregulated by Xoo infection but other OsPRI genes did not respond or rather suppressed, while all OsPR 1 genes were upregulated in compatible blast fungus interaction (Fig. 2a). 
Fig. 2 Response of $O s P R 1$ genes to pathogen infection. a Blast fungus infection. A conidia suspension of blast fungus race 003 was spray-inoculated onto Nipponbare (compatible, upper panel), and IL7 (incompatible, lower panel). The inoculated fourth leaves were harvested at 0,3 , and 6 days post inoculation (dpi) for RNA extraction. To semi-quantify the transcript level, RNA samples were subjected to $\mathrm{qPCR}$, and the relative expression levels compared with that of a control actin gene are shown. The transcript levels at time 0 , mock-inoculated, and blast-fungus inoculated leaves were shown as white, gray, and black columns, respectively. Bars indicate mean $\pm \mathrm{SD}$. The up-regulated genes by blast fungusinfection are marked with arrowheads. Gray arrowheads in the lower panel indicate early responsive genes. b Bacterial blight infection. The fourth leaves of Nipponbare rice plants were inoculated with a suspension of Xoo for bacterial blight disease, and the leaves were harvested at 0,4 , and 8 dpi for RNA extraction. The transcript level was analyzed by qPCR. The relative expression levels compared with that of the control actin gene are shown. Transcript levels at time 0 , mock-inoculated, and bacteria-blight inoculated leaves are shown as white, gray, and black columns, respectively. Xoo-upregulated and downregulated genes are marked with forward and reverse arrowheads, respectively. Bars indicate mean $\pm \mathrm{SD}$
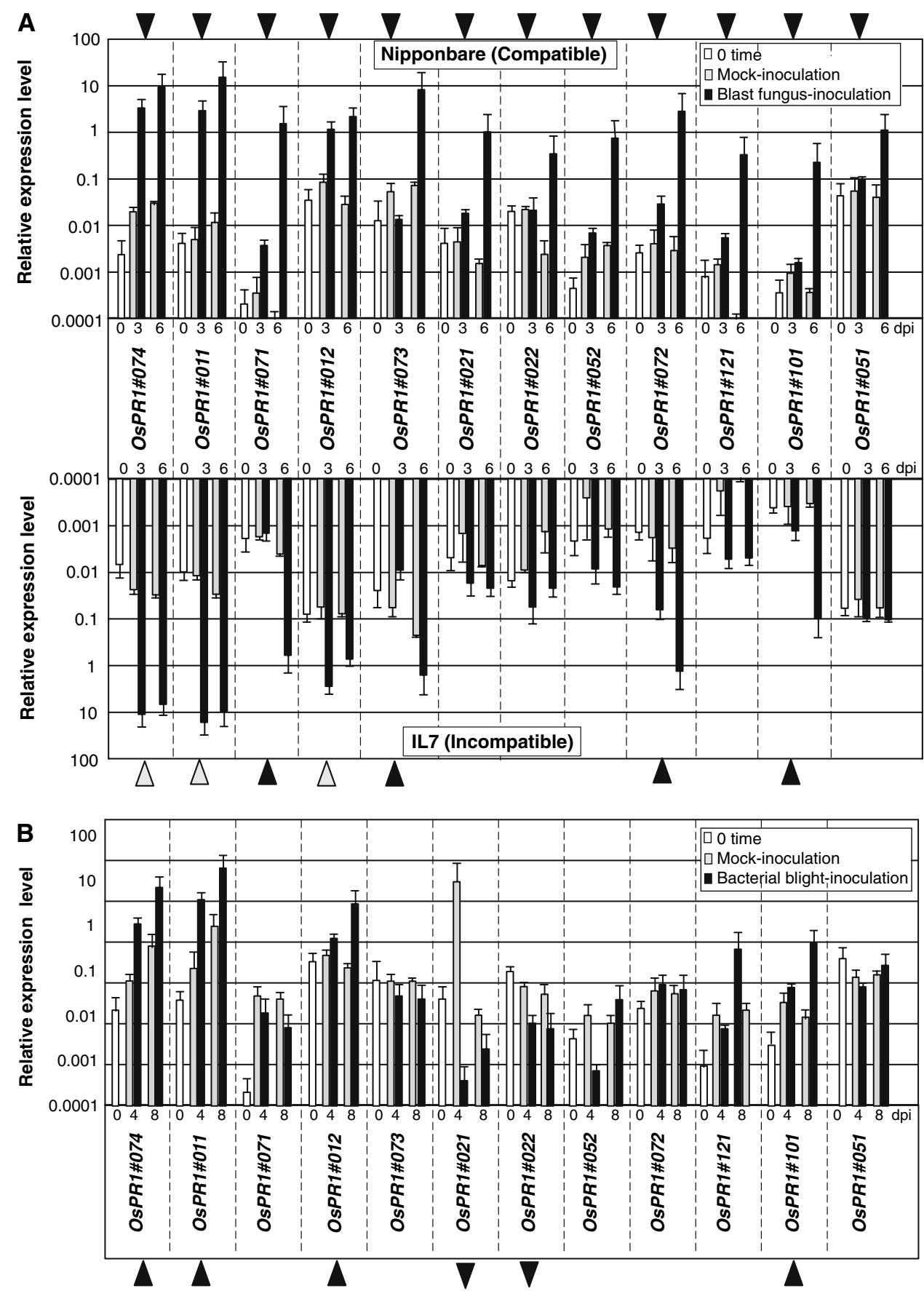

Wound-induced expression of OsPR1 genes in young rice plants

To study the response of $O s P R l$ genes to wounding, the fourth leaves were wounded by cross cutting. Triplicate samples were extracted at $0,1,6$, and $24 \mathrm{~h}$ after wounding, and used for qPCR. Among the 12 genes, OsPRI\#074 was wound-inducible with peak accumulation of the transcript at $6 \mathrm{~h}$ after wounding, and OsPRI\#051 was found to be an early wound-responsive gene (Fig. 3, forward arrowheads).
The OsPRI\#121 and \#052 transcripts decreased in response to wounding (reverse arrowheads) (Fig. 3).

Organ specific expression of OsPR1 genes

The basal transcript levels in various organs varied according to each gene; in the roots of healthy young rice plants at the 4-leaf stage, the transcript levels of the 5 genes, OsPR1\#074, $\# 071, \# 073, \# 072$, and \#101, were clearly higher than in the fourth leaves (Fig. 4) (open arrowheads). In flowers, the 


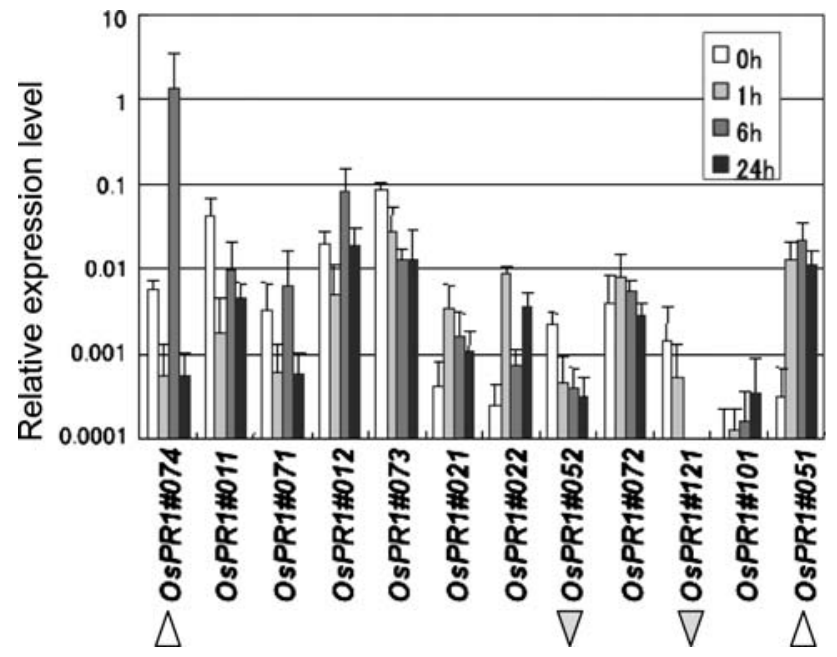

Fig. 3 Response of $O S P R 1$ genes to wounding The fourth leaves were cut into $1 \mathrm{~cm}$ length sections for wounding, and floated on water for 0 , 1,6 , and $24 \mathrm{~h}$ under light, and then the leaf pieces were homogenized for RNA extraction. Relative expression levels compared with that of the control actin gene are shown. The wound-upregulated and -downregulated genes are marked with forward or reverse arrowheads, respectively. Bars indicate mean \pm SD

basal transcript levels of five genes, OsPRI\#074, \#011, \#012, $\# 121$, and \#051, were at a high level (gray arrowheads). These results indicate that the organ-specific expression profiles of $O s P R 1$ genes varied considerably. The OsPRI\#074, $\# 071, \# 073$, and \#072, which are located on chromosome 7, were highly expressed in healthy roots. In healthy flowers the expression levels of five genes, OsPR\#074, \#011, \#012, $\# 121$, and \#051, were also higher.

Responses of OsPR1 genes to defense signal compounds in young rice plants

The responses of OsPRI genes to defense signal compounds were studied. Intact young rice plants in soil pots were dipped in water, SA, or ACC solutions, or exposed to the vapor of MeJA. RNA from the fourth leaves was subjected to qPCR (Fig. 5). OsPRI\#074 and \#101 were upregulated by all three signal compounds tested, while OsPRI\#071, \#073, \#021 and \#121 were upregulated by JA but not by ACC or SA. OsPRI\#074, \#011, and \#012, which were early responsive genes to blast fungus (Fig. 2), were SA-inducible. OSPRI\#011 was upregulated by SA but suppressed by ACC. Among the six genes that were inducible by the wound signal compound JA, OsPRI\#074 and \#051 were also upregulated by wounding (Fig. 3). OsPRI\#022 and \#052 were not particularly sensitive to any of these compounds. OsPRI\#011 and \#072 were downregulated by ACC and SA respectively, and OsPRI\#071 was downregulated by both ACC and SA.

Comparison of the defense-signaling pathways conferred by ACC, SA, and JA in rice with those in tobacco and Arabidopsis

Using the 12 OsPRI genes as probes, we analyzed the relationship of responsiveness to three defense signal compounds in rice. In tobacco, SA signaling was antagonistic to JA signaling on $P R$ gene expression: Niki et al. (1998) showed that the expression of acidic $P R 1,2$, and 3 genes was upregulated by SA-treatment and it was suppressed in the presence of JA in a dose-dependent manner, while the expression of basic $P R 2,5$, and 6 genes was upregulated by JA and suppressed by SA. Thomma et al. (1998) reported that the JA-signaling pathway is different from the SAsignaling pathway in Arabidopsis. Glazebrook et al. (2003) reported that the expression patterns of some genes revealed mutual inhibition between SA- and JA-dependent signaling using global expression phenotyping analysis of mutant Arabidopsis plants. Synergistic induction by ET and JA was reported in basic tobacco $P R$ genes (Xu et al. 1994).
Fig. 4 Organ-specific expression of $O S P R 1$ genes Leaves and roots of the seedlings at the fourth leaf stage (left panel), and flowers of adult plants (right panel) were subjected to qPCR analysis. Relative expression levels compared with that of the control actin gene are shown. The genes that express at a high level in roots and flowers are marked with white and gray arrowheads, respectively. Bars indicate mean $\pm \mathrm{SD}$

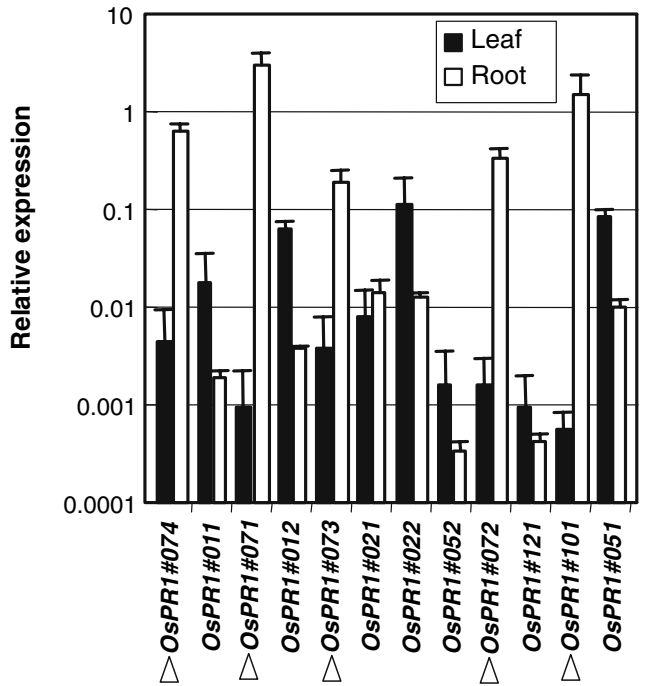




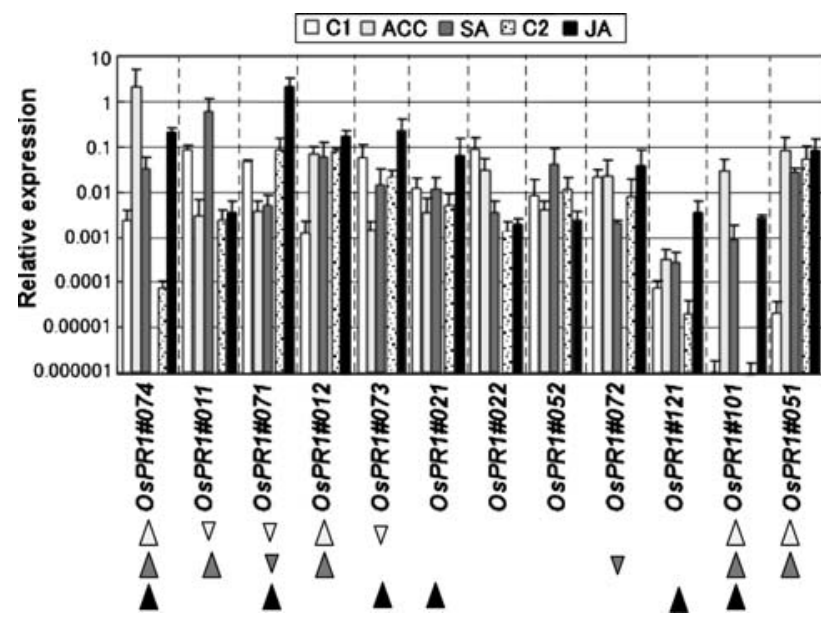

Fig. 5 Response of $O s P R 1$ genes to defense-signal compounds ACC, $\mathrm{SA}$, and JA. Expression levels of each $O S P R 1$ gene in fourth leaves at $24 \mathrm{~h}$ after treatment with defense-signal compounds were analyzed by qPCR. Relative expression levels compared with that of the control actin gene are shown. The ACC-, SA-, and JA-inducible genes are marked with gray, dark gray, and black arrowheads, respectively. For ACC or SA treatment, plastic pots with rice seedlings were dipped in solutions containing $1 \mathrm{mM}$ ACC or $3 \mathrm{mM}$ SA solution, and incubated for $24 \mathrm{~h}$ in the greenhouse. $C 1$ control for ACC- and SA-treatment (leaves of water treated plant); For JA treatment, pots with seedlings each was put in an air-tight clear plastic box, and a cotton pad with volatile methyl jasmonate (MeJA) dissolved in $\mathrm{EtOH}$ was put at the corner of the box to give a final concentration of $100 \mu \mathrm{M}$, and incubated for 24 h. $C 2$ control for JA-treatment (leaves of plant treated with $0 \mu \mathrm{M}$ of $\mathrm{JA})$, bars indicate mean $\pm \mathrm{SD}$

However, the expression patterns of $O S P R I$ genes in Fig. 5 showed no clear mutual inhibition between SA- and JAdependent signaling, except for OSPRI\#071. We further analyzed the relationship by means of Pearson's correlation coefficient (Fig. 6). Correlation coefficients for SA versus ACC, ACC versus JA, and SA versus JA were $0.75,0.61$, and 0.22 , respectively. The linear correlation coefficient, $r$, represents the strength and the direction of the linear relationship between two variables. A correlation of +1 means an increasing linear relationship and complete correlation,

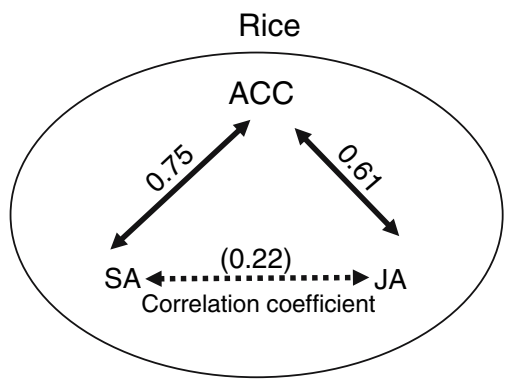

Fig. 6 Relationship of the three signaling pathways in $O s P R 1$ genes. Based on the data in Fig. 5, the response of young rice plants to ACC-, SA-, or JA-treatments was compared with other treatments, and the correlation coefficients between the responses to pairs of signals were calculated. See the text for details while -1 means a decreasing linear relationship. Cohen (1988) proposed that $|r|$ below 0.1 is regarded as insubstantial, $0.1 \leq|r|<0.3$ as weak, $0.3 \leq|r|<0.5$ as medium, and $0.5 \leq|r|<1.0$ as strong correlation. While, levels of statistical significance at 5 and $1 \%(n=12)$ are 0.576 and 0.708 , respectively. The $r$ values in Fig. 6 suggest synergism between ACC versus SA and ACC versus JA, and low or no correlation between SA versus JA rather than antagonism.

Tissue specific expression of a representative OsPR1 gene in rice plants

Analysis of the tissue specific expression of rice $P R I$ gene by means of histological studies has not been performed previously. To study the tissue specific expression profiles of a representative $O S P R 1$ gene, we selected $O S P R I \# 074$ because it clearly responded to both compatible and incompatible fungal interactions, bacterial bright infection, wounding and the 3 defense signal compounds. The promoter sequence of OsPRI\#074 was obtained by PCR amplification from the Nipponbare genome. The promoter sequence, containing $1,919 \mathrm{bp}$, was inserted into the pTH2 vector (Kawahigashi et al. 2007) to construct the plasmid PRIT::GUS, which contains the promoter and the coding region for 16 amino acids of the N-terminus of the OsPR 1 protein to express the GUS protein effectively as a translational fusion (Fig. 7a). The OSPRIT::GUS gene was introduced into rice plants (Oryza sativa cv. Nipponbare). Among 30 hygromycin-resistant plants regenerated, three independent lines were selected as representatives exhibiting a negligible level of GUS activity in healthy leaves and more than 30-fold higher levels after wounding or inoculation with a conidia suspension of $M$. grisea. The OSPRIT::GUS plants of the second or third generation were subjected to histological GUS analysis using X-gluc as the substrate.

Figure 7B shows the localization of GUS activity in healthy 5-day-old transgenic rice seedlings. A high level of GUS activity was detected in the primary root (arrows, Fig. 7B a-c) and the root tip (arrowheads), but it was absent or considerably reduced in the elongation zone (white arrowheads). In cross sections of the middle part of the root $80 \mu \mathrm{m}$ in thickness (Fig. 7B e), a strong GUS activity was detected in the vascular cylinder (vc) and sclerenchyma (sc), and a weak activity in the cortex (co). GUS staining was found in the slit surface of the coleoptile (yellow arrowheads, Fig. 7B a, b), and on the surface of unhulled rice (white arrow, Fig. 7B a, f). In the anther, a weak blue staining was found in the matrix of pollen loculus (data not shown). In the vector control plants, no GUS activity was detected in roots (Fig. 7B d) or any other part analyzed under these in condition (data not shown). 
Fig. 7 Histological analysis of $O s P R 1 \# 074$ gene expression in transgenic rice plants. a Schematic diagram showing the construct of the introduced gene. The promoter sequence of OsPR1\#074 was used. b Localized GUS staining in healthy 5 day-old transgenic rice seedlings $(a-e)$. Because similar expression profiles were obtained in three independent transgenic lines, the data from a representative line is shown. $f$ unhulled rice. c GUS staining of 2 month-old transgenic rice plants. $a$ Healthy roots, $b$ roots at 2 days after wounding, $c-e$ leaves at 2 days after wounding. d GUS staining assay of 4 th leaves at $5(a, c, d)$ or 11 (b) dpi. Black arrows indicate stained mesophyll tissue. Brown arrows indicate the necrotic regions
A

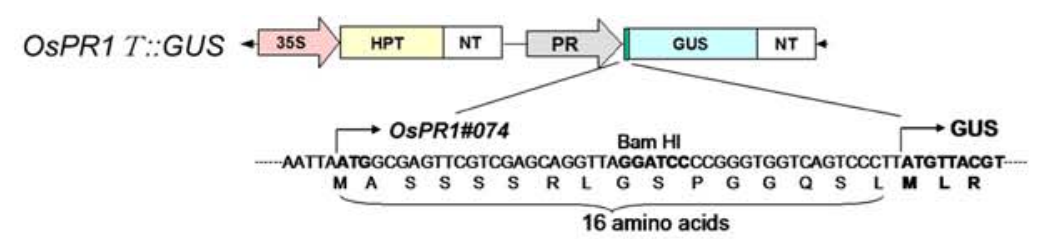

B

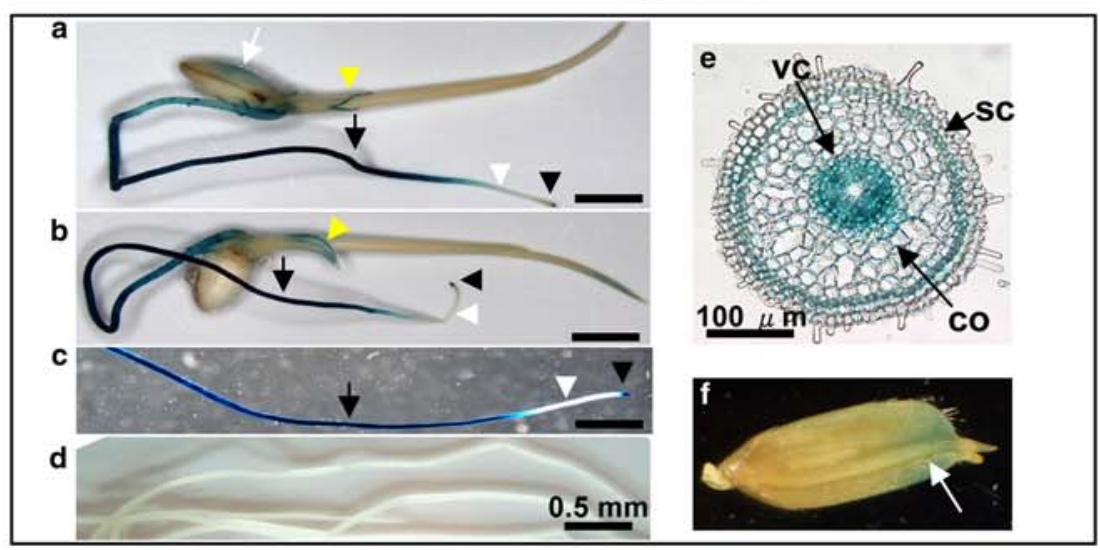

C

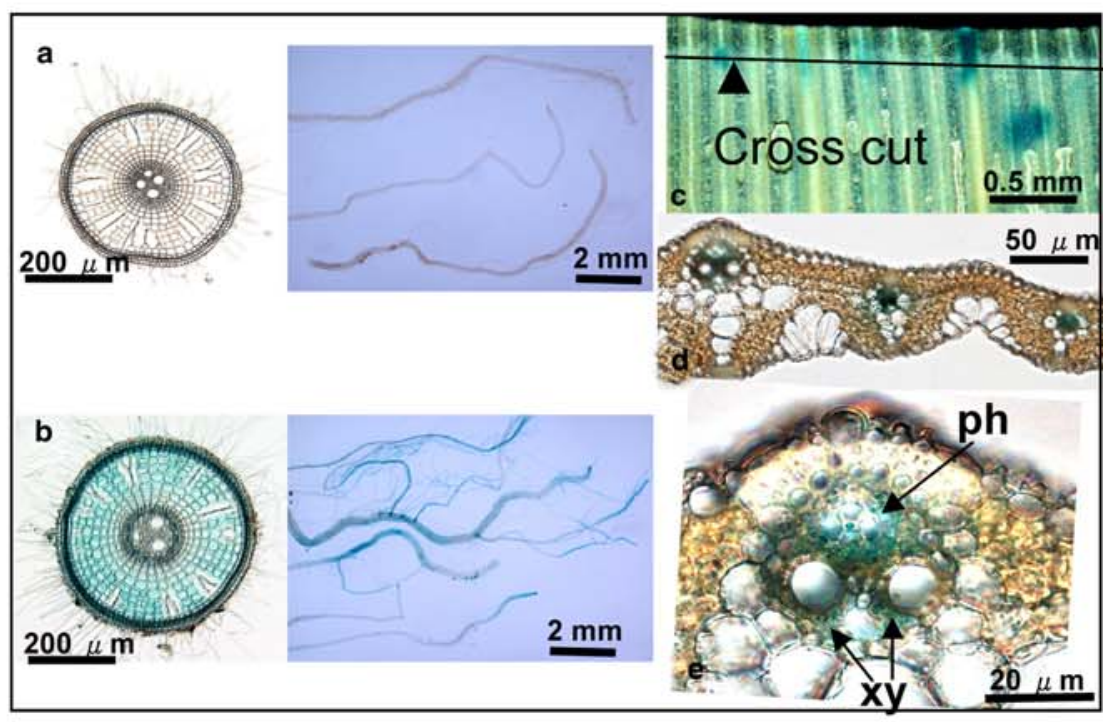

D

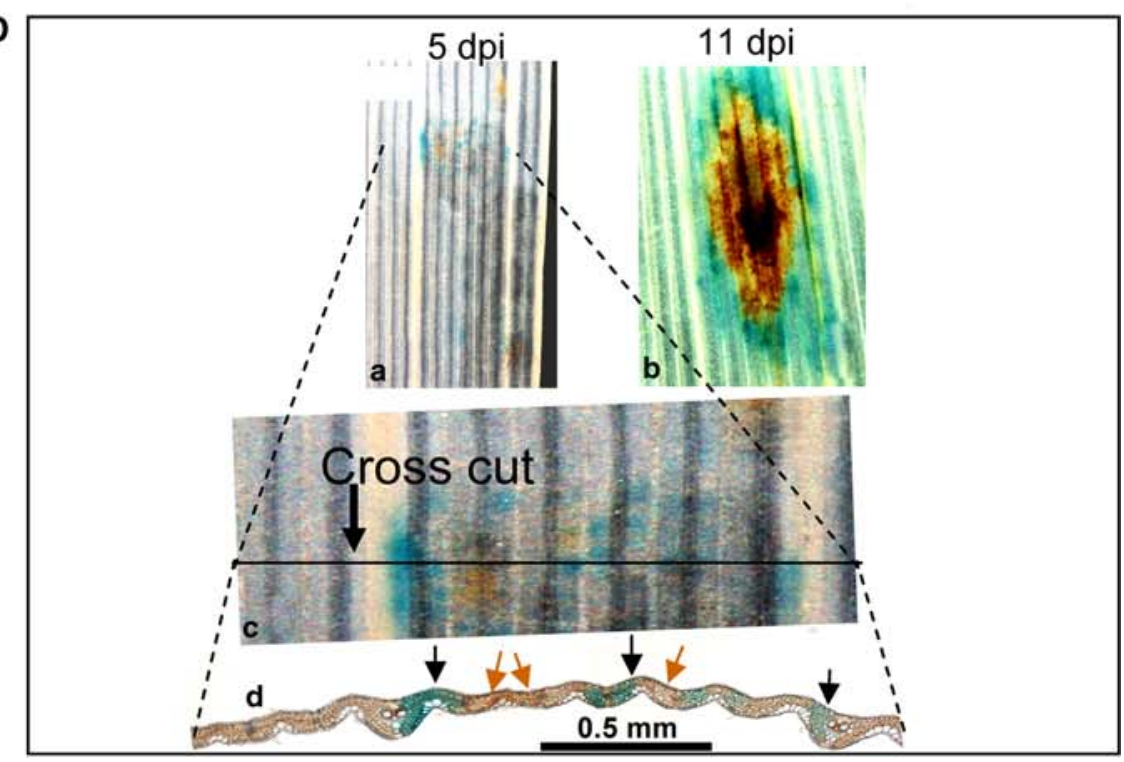


In 2 month-old OSPRIT::GUS plants, no GUS activity was found in healthy roots (Fig. 7C a), while high levels of GUS activity were found in healthy 5 day-old (Fig. 7Ba, b, and c) and 2 week-old (data not shown) plants. Thus, $O S P R 1$ expression in roots is likely to be regulated developmentally. Wounding induced a high level of GUS activity in the roots of 2-month-old plants. When the aerial parts were removed by cross cut from of the plants, a strong GUS activity was induced in the roots of cut plants at 2 days after cutting (Fig. 7C b). In cross sections of the root in the middle region, GUS staining was found in all tissues, including the vascular cylinder, cortex, and sclerenchyma. No detectable GUS activity was found in healthy leaves of transgenic rice plants (data not shown); however, wounding induced a strong GUS activity in the neighbor region of the cut surface especially in the vascular systems including xylem parenchyma (xy) and phloem (ph) (Fig. 7C c-e).

Next, GUS activity in rice leaves infected with blast fungus was analyzed. In the compatible cultivar (WT) lacking the $P i$-iresistance gene, enlarged lesions were found 3-5 days after inoculation developing in size with time and with conidia formation on the infected leaf surface. After GUS staining, many blue spots were found at or around the lesions in the leaves 5 days after inoculation (Fig. 7D a). When the leaf of Fig. 7D a was cross cut at the marked line, and shown in Fig. 7D c, the blue staining was found tolocalize in the mesophyll cells (black arrows) around the necrotic regions (brown arrows, Fig. 7D d). At 11 days after inoculation, GUS activity was found around the necrotic lesions (Fig. 7D b).

\section{Discussion}

We studied here the response of 12 OSPRI genes to pathogens, wounding, and defense signal compounds and their constitutive expression in organs. This is the first example of a comparative study on the characterization of a set of $P R 1$ family genes by qPCR, a high throughput method. The 12 genes include PRla and $b$, which have been reported as pathogen-inducible genes by Agrawal et al. (2001), and ten of the 12 genes are contained in the 32 listed rice $P R I$-like genes including at least 3 pseudogenes whose expression profiles were not obvious (van Loon et al. 2006). We searched rice PRl-like genes from fulllength cDNA (http://www.cdna01.dna.affrc.go.jp/cDNA) and EST (http://www.riceblast.dna.affrc.go.jp/). Because strongly expressed genes should be easily extracted from the databases for expressed genes, a majority of highly expressed rice $P R I$-like genes are thought to be contained in the 12 genes. The sequences of the 12 OsPR 1 proteins were well conserved with complete matches in 10 amino acid residues in the $\mathrm{C}$-terminal half (Fig. 1a). Because the
10 residues were also very well conserved in all 36 PR1type proteins selected from 14 different plant species including Brassica napus, Hordeum vulgare, Lycopersicon esculentum, Medicago trunculata, Triticum aestivum, and Zea mays (van Loon and van Strien 1999), these regions in the C-terminus should be important for the putative functions of PR1 proteins in plants.

All 12 OsPRI genes selected here were clearly upregulated in a compatible rice-blast fungus interaction, indicating that they really are pathogen related. Notable is that the induction pattern of each $O S P R I$ gene by different pathogen-host interactions was characteristic (Fig. 2). Four genes, OsPR1\#074, \#011, \#012, and \#101, responded positively to blast fungus infection in both compatible and incompatible interactions, and also to Xoo infection. Among these, OsPRI\#074, \#011, and \#012 were responsive to blast fungus in the early infection period in both interactions. Conversely, the expression of OSPRI\#021 and $\# 022$ was reduced by Xoo infection compared with the control after mock-inoculation, which is a wound treatment. Assuming that Xoo infection may inhibit wound-induced expression of these genes, it is consistent that they are wound-inducible (Fig. 3). The above result that "all 12 $O S P R I \mathrm{~s}$ are characteristically pathogen inducible" is apparently different from the data of Arabidopsis where only one PRI gene was pathogen-inducible (AT2g14610) among 22 predicted Arabidopsis PRl genes (van Loon et al. 2006). We studied this result using an AtGenExpress Visualization Tool from http://www.arabidopsis.org/, and confirmed that only the $P R l$ gene was upregulated by infection with either Pseudomonas syringae pv. tomato DC3000 or Pytophythora infestans, and the other $P R 1$ genes were not. The reason for different responses of $P R I$ s to pathogen infection in rice and Arabidopsis is not clear, but we could speculate that $O s P R l$ s have evolved in the rice genome to provide resistance to a broad range of pathogens, but a limited set of Arabidopsis PRIs has evolved to respond to pathogens.

In rice, the level of free SA in young healthy rice leaves was as high as about $10 \mu \mathrm{g}$ per $\mathrm{g}$ fresh leaf (Silverman et al. 1995), but it was only about $20 \mathrm{ng}$ (Seo et al. 2007) or $100-200 \mathrm{ng}$ (Silverman et al. 1995) in tobacco leaves, and about $30 \mathrm{ng}$ (Park et al. 2007) or $150 \mathrm{ng}$ (our unpublished data) in Arabidopsis leaves. Thus, the SA content in rice leaves corresponds to 50- to 500-fold of that in tobacco or Arabidopsis leaves, which is comparable to the induced SA level after HR lesion formation by TMV-infection. Such a high SA level in rice plants could affect $O s P R I$ expression after pathogen infection, treatment with SA, JA, or ACC, and wounding. Actually, the responses of the $O S P R I$ genes to defense signal compounds indicate that the signaling pathways in rice conferred by SA and JA were synergistic as well as that by ET and JA, and SA and ET (Fig. 6). This finding is considerably different from the "antagonistic rela- 
Fig. 8 Comparison of expression characteristics of $O S P R I$ genes Induction levels of $O s P R 1$ genes by pathogens, wounding, and defense signal compounds, and their constitutive expression levels in organs were compared. The transcript levels in healthy $4^{\text {th }}$ leaves are shown in the right most column. ++ very highly inducible or expressed gene, + highly inducible or expressed gene, \pm gene whose induction or expression was not clear, - not inducible or expressed gene

\begin{tabular}{|c|c|c|c|c|c|c|c|c|c|c|}
\hline \multirow{2}{*}{ OsPR1 gene } & \multicolumn{2}{|c|}{ M.grisea } & \multirow{2}{*}{$\begin{array}{c}\text { Xoo } \\
\text { Comp }\end{array}$} & \multirow{2}{*}{ Wound } & \multirow{2}{*}{$A C C$} & \multirow{2}{*}{ SA } & \multirow{2}{*}{$\mathrm{JA}$} & \multirow{2}{*}{ Root } & \multirow{2}{*}{ Flower } & \multirow{2}{*}{$\begin{array}{l}\text { Basal } \\
\text { (Leaf) }\end{array}$} \\
\hline & Comp & Incomp & & & & & & & & \\
\hline OsPR1\#074(OsPR1a) & ++ & $\begin{array}{c}3 \mathrm{dpi} \geq 6 \mathrm{dpi} \\
++\end{array}$ & ++ & $\begin{array}{c}6 \mathrm{~h} \\
++\end{array}$ & ++ & ++ & ++ & ++ & ++ & + \\
\hline OsPR1\#011(OsPR1b) & ++ & $\begin{array}{c}\text { 3dpi } \cong 6 \mathrm{dpi} \\
++\end{array}$ & ++ & - & - & + & - & + & ++ & + \\
\hline OsPR1\#071 & ++ & $\begin{array}{c}\text { 3dpi } \leq 6 \mathrm{dpi} \\
++\end{array}$ & - & - & - & - & ++ & ++ & - & + \\
\hline OsPR1\#012 & ++ & $\begin{array}{c}\text { 3dpi } 26 \mathrm{dpi} \\
++\end{array}$ & + & - & + & + & + & + & ++ & + \\
\hline OsPR1\#073 & ++ & $\begin{array}{c}\text { 3dpi } \cong 6 \mathrm{dpi} \\
++\end{array}$ & - & - & - & - & + & ++ & + & ++ \\
\hline OsPR1\#021 & ++ & + & - & + & - & - & \pm & + & + & + \\
\hline OsPR1\#022 & + & + & - & + & - & - & - & + & + & + \\
\hline OsPR1\#052 & + & + & - & - & - & \pm & - & - & + & \pm \\
\hline OsPR1\#072 & ++ & $\begin{array}{c}\text { 3dpi } \_6 \mathrm{dpi} \\
++\end{array}$ & - & - & - & - & - & ++ & + & + \\
\hline OsPR1\#121 & ++ & + & - & - & - & - & + & - & ++ & \pm \\
\hline OsPR1\#101 & ++ & \begin{tabular}{|c|} 
3dpi_zdpi \\
++ \\
\end{tabular} & + & \pm & ++ & + & + & ++ & + & \pm \\
\hline OsPR1\#051 & + & - & - & + & ++ & ++ & ++ & + & ++ & \pm \\
\hline
\end{tabular}

tionship of SA and JA signaling" found in tobacco (Niki et al. 1998) and Arabidopsis (Gupta et al. 2000). In tobacco, acidic PR1 proteins such as NtPR1a, b, and c were inducible by SA (Ohashi and Matsuoka 1987), which is a defense signal compound for systemic acquired resistance. The NtPRBIb (Eyal et al. 1992; Niki et al. 1998) and AtPRB1 (Santamaria et al. 2001) genes, which encode basic PR proteins in tobacco and Arabidopsis, respectively, were reported to respond positively to JA and ET, and negatively to SA. The Arabidopsis PRI gene (At2g14610) encodes a basic protein that is inducible by SA.

To compare the natures of the $O S P R I$ genes, the results of the expression of $12 O S P R I$ genes are summarized in Fig. 8. It is again impressive that the expression upregulated by various treatments differed considerably depending on the gene, and the transcript levels constitutively found in leaf, root, and flower also varied according to the genes. When comparing the four genes OsPRI\#071, \#72, \#073, and \#074, which are clustered in a locus on chromosome 7, we found the following common characteristics: all four genes (1) encode acidic proteins, (2) are constitutively expressed in healthy roots at a high level, and (3) are upregulated by blast fungus-infection. In spite of these similarities, their expression profiles after certain treatments were significantly different from each other. For example, (1) the transcript of OsPRI\#074 accumulated at an earlier time period than those of OsPRI\#071, \#072, or \#073 in fungusinfected resistant cultivar IL7, (2) OsPRI\#074 but not $\# 071$, \#072, or \#073 was upregulated by Xoo-infection, (3)
OsPRI\#074, but not OsPRI\#071, \#072, or \#073, was wound-inducible, (4) OsPRI\#074 was ACC-, SA-, and JAinducible, OsPRI\#071 was JA-inducible, OsPRI\#072 was not inducible by any signal compounds used here, and OsPRI\#073 appeared to be suppressed by ACC, (5) OsPRI\#074 was expressed in flowers at a high level, but OsPRI\#071, \#072, and \#073 were not.

From the expression characteristics of the 12 OsPRI genes obtained here, the possible contribution of all OsPRI genes for plant self-defense against pathogen attack was indicated. Although the functions of $O S P R I$ genes are not fully understood, PR1 proteins in some plant species have been reported to have antifungal activity including tobacco acidic PRIa overexpression that induced increased tolerance to two oomycete pathogens in tobacco (Alexander et al. 1993), and basic PR-1 proteins of tobacco and tomato, which have an antimicrobial activity against Phytophythora infestans (Niederman et al. 1995). Thus, the redundant expression of the 12 OSPRI genes may effectively contribute to defend the attack of various pathogens.

The expression levels of the 12 genes in healthy tissues and wounded leaves were also very different according to each particular gene. The data in Fig. 7 shows a representative example of tissue- and organ-specific expression of OSPRI. The level of GUS activity in transgenic rice plants carrying the OSPRIT::GUS gene was confirmed to be similar to the OSPRI\#074 transcript level as shown in tobacco PRla::GUS plants (Yamakawa et al. 1998), in which the GUS gene was expressed as a similar translational fusion 
gene described in Fig. 7A. GUS analysis using independent transgenic lines showed OSPRI\#074 expression was developmentally regulated in roots and constitutively expressed in young rice plants, but not in 2-month old plants, in which the expression was strongly upregulated by wounding (Fig. 7A, B). The wound-induced OsPRI\#074 expression in adult plants was localized mainly in the vascular system, which is important as the sensing tissue of the water pressure change after wounding and as the site of bacterial pathogen propagation.

The information on the $12 P R 1$ genes obtained here will be useful for further studies on self-defense mechanisms in rice plants, and for the usage of each $P R I$ gene as a characteristic marker gene.

Acknowledgments We thank Imbe T and Ando I of the National Agriculture and Food Research Organization for providing IL7 rice seeds, Miyasaka A in the same organization for providing $M$. grisea race 003 and Y. Gotoh, Y. Naito, and M. Teruse for their technical assistance. This study was supported in part by the Program for Promotion of Basic Research Activities for Innovative Biosciences.

Open Access This article is distributed under the terms of the Creative Commons Attribution Noncommercial License which permits any noncommercial use, distribution, and reproduction in any medium, provided the original author(s) and source are credited.

\section{References}

Agrawal GK, Jwa NS, Rakwal R (2000a) A novel rice (Oryza sativa $L$.) acidic PR1 gene highly responsive to cut, phytohormones, and protein phosphatase inhibitors. Biochem Biophys Res Commun 274:157-165

Agrawal GK, Rakwal R, Jwa NS (2000b) Rice (Oryza sativa L.) OsPRIb gene is phytohormonally regulated in close interaction with light signals. Biochem Biophys Res Commun 278:290-298

Agrawal GK, Rakwal R, Jwa NS, Agrawal VP (2001) Signaling molecules and blast pathogen attack activates rice OsPR1a and OsPR1b genes: a model illustrating components participating during defense/stress response. Plant Physiol Biochem 39:10951103

Alexander D, Goodman RM, Gut-Rella M, Glascock C, Weymann K, Friedrich L, Maddox D, Ahl-Goy P, Luntz T, War E, Ryals J (1993) Increased tolerance to 2 oomycete pathogens in transgenic tobacco expressing pathogenesis-related protein 1a. Proc Natl Acad Sci USA 90:7327-7331

Cohen J (1988) Differences between correlation coefficients. In: Cohen J (ed) Statistical power analysis for the behavioral sciences, 2nd edn. Lawrence Erlbaum Associates Publishers, Hillsdale, pp 109143

Eyal Y, Sagee O, Fluhr R (1992) Dark-induced accumulation of a basic pathogenesis-related (PR-1) transcript and a light requirement for its induction by ethylene. Plant Mol Biol 19:589-599

Glazebrook J, Chen W, Estes B, Chang HS, Nawrath C, Metraus JP, Zhu T, Katagiri F (2003) Topology of the network integrating salicylate and jasmonate signal transduction derived from global expression phenotyping. Plant J 34:217-228

Gupta V, Willits MG, Glazebrook J (2000) Arabidopsis thaliana EDS4 contributes to salicylic acid (SA)-dependent expression of defense responses: evidence for inhibition of jasmonic acid signaling by SA. Mol Plant Microbe Interact 13:503-511
Ise K, Horisue N (1988) Characteristics of several near-isogenic lines of rice for blast resistance gene. Breed Sci 38(Suppl 2):404-405

Iwai T, Miyasaka A, Seo S, Ohashi Y (2006) Contribution of ethylene biosynthesis for resistance to blast fungus infection in young rice plants. Plant Physiol 142:1202-1215

Iwai T, Seo S, Mitsuhara I, Ohashi Y (2007) Probenazole-induced accumulation of salicylic acid confers resistance to Magnaporthe grisea in adult rice plants. Plant Cell Physiol 48:915-924

Kawahigashi H, Hirose S, Iwai T, Ohashi Y, Sakamono W, Maekawa M, Ohkawa Y (2007) Chemically induced expression of rice $O S B 2$ under the control of the OSPR1.1 promoter confers increased anthocyanin accumulation in transgenic rice. J Agric Food Chem 55:1241-1247

Metzler MC, Cutt JR, Klessig DF (1991) Isolation and characterization of a gene encoding a PR-1-like protein from Arabidopsis thaliana. Plant Physiol 96:346-348

Niederman T, Genetet I, Bruyere T, Gees R, Stinzi A, Legrand M, Fritig B, Mosinger E (1995) Pathogenesis-related PR-1 proteins are antifungal: isolation and characterization of three 14 kidodalton proteins of tomato and of a basic PR-1 of tobacco with inhibitory activity against Phytophythora infestans. Plant Physiol 108:17-27

Niki T, Mitsuhara I, Seo S, Ohtsuba N, Ohashi Y (1998) Antagonistic effect of salicylic acid and jasmonic acid on the expression of pathogenesis-related (PR) protein genes in wounded mature tobacco leaves. Plant Cell Physiol 39:500-507

Ohashi Y, Matsuoka M (1987) Induction and secretion of pathogenesis-related proteins by salicylate or plant hormones in tobacco suspension cultures. Plant Cell Physiol 28:573-580

Ohshima M, Matsuoka M, Yamamoto N, Tanaka Y, Kano-Murakami Y, Ozeki Y, Kato A, Harada N Ohashi Y (1987) Nucleotide sequence of the PR-1 gene of Nicotiana tabacum. FEBS Lett 225:243-246

Ohshima M, Itoh H, Matsuoka M, Murakami T, Ohashi Y (1990) Analysis of stress-induced or salicylic acid-induced expression of the pathogenesis-related 1a protein gene in transgenic tobacco. Plant Cell 2:95-106

Park S-W, Kaimoyo E, Kumar D, Mosher S, Klessig DF (2007) Methyl salicylate is a critical mobile signal for plant systemic acquired resistance. Science 318:113-116

Santamaria M, Thomson CJ, Read ND Loake GJ (2001) The promoter of a basic PR1-like gene, AtPRB1, from Arabidopsis establishes an organ-specific expression pattern and responsiveness to ethylene and ethyl jasmonate. Plant Mol Biol 47:641-652

Sasaki K, Iwai T, Hiraga S, Kuroda K, Seo S, Mitsuhara I, Miyasaka A, Iwano M, Ito H, Matsui H, Ohashi Y (2004) Ten rice peroxidases redundantly respond to multiple stresses including infection with rice blast fungus. Plant Cell Physiol 45:1442-1452

Seo S, Katou S, Seto H, Gomi K, Ohashi Y (2007) The mitogen-activated protein kinases WIPK and SIPK regulate the levels of jasmonic and salicylic acids in wounded tobacco plants. Plant $\mathrm{J}$ 49:899-909

Silverman P, Seskar M, Kanter D, Schweizer P, Metraus JP, Raskin I (1995) Salicylic acid in rice (biosynthesis, conjugation, and possible role). Plant Physiol 108:633-639

Schweizer P, Buchala A, Silverman P, Seskar M, Raskin I, Metraux JP (1997) Jasmonate-inducible genes are activated in rice by pathogen attack without a concomitant increase in endogenous jasmonic acid levels. Plant Physiol 114:79-88

Thomma BP, Eggermont K, Penninckx IA, Mauch-Mani B, Vogelsang R, Cammue BP, Broekaert WF (1998) Separate jasmonatedependent and salicylate-dependent defense-response pathways in arabidopsis are essential for resistance to distinct microbial pathogens. Proc Natl Acad Sci USA 95:15107-15111

Toki S, Hara N, Ono K, Onodera H, Tagiri A, Oka S, Tanaka H (2006) Early infection of scutellum tissue with Agrobacterium allows high-speed transformation of rice. Plant J 47:969-976 
van Loon LC, van Strien EA (1999) The families of pathogenesisrelated proteins, their activities and comparative analysis of PR-1 type proteins. Physiol Mol Plant Path 55:85-97

van Loon LC, Rep M, Pieterse CMJ (2006) Significance of inducible defense-related proteins in infected plants. Annu Rev Phytopathol 44:135-162

Xu Y, Chang P-F L, Liu D, Narasimhan ML, Raghothama KG, Haegawa PM, Bressan RA (1994) Plant defense genes are synergistically induced by ethylene and methyl jasmonate. Plant Cell 6:1077-1085
Yamada M, Kiyosawa S, Yamaguchi T, Hirano T, Kobayashi T, Kushibuchi K, Watanabe S (1976) Proposal of a new method for differentiating races of Pyricularia oryzae Cavara in Japan. Ann Phytopathol Soc Jpn 42:216-219

Yamakawa H, Kamada H, Satoh M, Ohashi Y (1998) Spermine is a salicylate-independent endogenous inducer for both tobacco acidic pathogenesis-related proteins and resistance against tobacco mosaic virus infection. Plant Physiol 118:1213-1222 